Open Access

\title{
Comparing videos and a 3D virtual environment for teaching school-related functional skills and behaviors to students with ADHD or developmental dyslexia, displaying challenging behaviors: a case study
}

\author{
Emmanuel Fokides ${ }^{1,3^{*}}$ (D), Maria-loanna Chronopoulou ${ }^{1}$ (D) and Polyxeni Kaimara ${ }^{2}$ (D)
}

\footnotetext{
*Correspondence: fokides@aegean. gr ${ }^{1}$ Department of Primary Education, University of the Aegean, Rhodes, Greece

${ }^{3} 1$ Dimokratias str., 85132, Rhodes, Greece

Full list of author information is available at the end of the article
}

\begin{abstract}
The study presents the results of a comparative study in which videos and a 3D virtual environment were used for teaching school-related functional skills to students with ADHD or developmental dyslexia, displaying challenging behaviors. The participating students (sixteen 8 to 9 years old) were divided into two groups. To the first, videos were used and the second used the virtual environment. To both, a school environment was presented, students observed how they were expected to behave, and had to demonstrate what they have learned. Each student attended a total of three two-hour sessions. Data were collected by means of observations. The results indicated that students in the second group significantly improved their functional skills in terms of the number of behaviors that were retained and manifested in the real school environment. Thus, it can be argued that virtual environments are a promising tool for teaching functional skills to students with ADHD or developmental dyslexia, displaying challenging behaviors. Implications for research and practice are also discussed.
\end{abstract}

Keywords: Behaviors, Functional skills, Opensimulator, Special education, Virtual environments

\section{Introduction}

The objective of the inclusion of children with special educational needs in mainstream primary schools is to prevent social discrimination. Then again, this initiative is not free of challenges, especially for the students in need of special care. Not only their academic performance is inconsistent with that of their peers, but they may present a wide spectrum of incapacities, such as health issues, cognition deficits, impaired social and emotional dexterities, and mental impairments (Espelage et al. 2016). Inevitably, these often lead to challenging situations in their everyday school life, isolation, outbursts of anger, and non-functional social interactions (Nye et al. 2016; Vlachou et al. 2016). The chances of students with special educational needs to manifest undesirable

(c) The Author(s). 2019 Open Access This article is distributed under the terms of the Creative Commons Attribution 4.0 International License (http://creativecommons.org/licenses/by/4.0/), which permits unrestricted use, distribution, and reproduction in any medium, provided you give appropriate credit to the original author(s) and the source, provide a link to the Creative Commons license, and indicate if changes were made. 
behaviors are high, as are the chances of being victimized (Thompson et al. 1994). Structured interventions or holistic programs aiming to support their well-being and academic performance, as well as their everyday functional skills (within and outside the school environment), are the norm (Rose et al. 2015). Such programs try to enhance their behavioral, emotional, and communication skills (e.g., Blandon et al. 2010; Domitrovich et al. 2007; Espelage et al. 2016).

While the focus of special education is on students facing severe issues, there is another category of students with special educational needs that receives considerably lower attention. This category includes students with minor or mild impairments, for example, with attention-deficit/hyperactivity disorder (ADHD) or developmental dyslexia. Programs trying to accommodate the needs of such students are far fewer and the emphasis often lies in their academic needs; issues regarding their social adjustment are neglected (Office of Special Education and Rehabilitative Services 2015) and the same applies to interventions trying to enhance their social skills (Garrote et al. 2017).

Among the most commonly used tools in special education are videos, through the practice of video-modeling, which, essentially, is the utilization of videos for teaching students with impairments the targeted behaviors/skills (Mason et al. 2013). Indeed, a significant number of studies still provide support for the use and efficacy of this tool. For example, videos were used for supporting students' behavior (Mason et al. 2013; Wang et al. 2011) and for fostering their social skills (Hirsch et al. 2019; Kennedy and Swain-Bradway 2012), even to the ones with multiple difficulties (Kanfush and Jaffe, 2019). The foundations of this instructional technique lie in the principles of observational learning (Miltenberger and Charlop 2015). The anticipated behaviors/skills (the ones that are modeled) are presented in a video clip, the child watches it, and then has the opportunity to practice them. This constitutes the basic video modeling, which is the simplest form. In video prompting, the video presenting the desired behavior/skill is broken into small segments/steps, a single step is presented, and the individual is prompted to perform this step before continuing to the next one (Kellems and Edwards 2016). Another form is group video-modeling. As the term implies, a group of individuals is engaged in the desired behavior (e.g., a group of students moving quickly and quietly from one classroom to another) (McNiff et al. 2019).

Although videos are commonly used for behavioral modification or for teaching functional skills to students with special educational needs, other technological tools are used as well. One such tool is 3D virtual environments (VEs), an umbrella term for a family of technologies such as virtual reality and extended reality. In short, VEs are realistic representations of an imaginary or real environment in which users can interact with the virtual objects in a lifelike manner (Freina and Ott 2015). Because of VEs' verisimilitude, users feel the senses of presence and immersion; in essence, they lose track of reality and consider the VEs as real (Portman et al. 2015). As will be presented in the coming section, VEs are used quite extensively in special education.

Taking into account that: (i) effective strategies for enhancing the functional living skills of students with mild impairments (i.e., students diagnosed with ADHD or developmental dyslexia) need to be further explored and (ii) VEs can be an effective teaching tool, a project was designed and implemented. Its objective was to compare VEs and videos in an effort to determine whether the former are more effective than the latter in terms of modifying the behaviors/skills of students diagnosed with ADHD or 
developmental dyslexia. The skills/behaviors were related to how students are expected to function in the school environment. The rationale, methodology, and results of the project are presented in the coming sections.

\section{Background}

Students with milder impairments (such as ADHD or developmental dyslexia) receive less attention in terms of organized interventions aiming to accommodate their needs and are mostly focused on improving their academic performance. Then again, as it will be further elaborated in the coming paragraphs, they face quite a lot of functional, emotional, and social challenges due to their impairments' secondary consequences. Not only that, but their behavior is often challenging, rendering their adjustment to the school environment rather challenging.

Although the exact etiology of ADHD still remains unclear, its mean prevalence (worldwide) is estimated to be around 2.2\% (Fayyad et al. 2017). Individuals with ADHD display a variety of symptoms all related to attentional problems and excessive activity. They might have challenges in paying attention, focusing on a task, or following instructions; they may be easily distracted and/or forget easily; they tend to lack persistence or they get easily bored when an activity requires cognitive involvement; they tend to jump from one activity to another (without competing either); they are often disorganized, inattentive, impulsive, and hyperactive (International Statistical Classification of Diseases and Related Health Problems 2016). Moreover, adolescents with ADHD seem not to take into account the consequences of their behavior, which is often disruptive and inappropriate for their age (American Psychiatric Association 2013). Their emotional awareness is often limited (Factor et al. 2016) and, in general, they may have trouble regulating their emotions (Faraone et al. 2019). Due to the above, they often have disciplinary trouble, as they unthinkingly break the rules. Secondary complications may include antisocial behavior and low self-esteem resulting either in isolation or in being unpopular among their fellow classmates (International Statistical Classification of Diseases and Related Health Problems 2016). Impaired cognitive functions and developmental delays in language are alarmingly frequent (Dyck and Piek 2014).

Individuals with dyslexia mainly have trouble with reading despite having normal intelligence (Siegel 2006). The term "developmental dyslexia" is used for describing the form of dyslexia probably caused by genetic factors, in contrast to "acquired dyslexia" or "alexia" which can occur due to brain damage during an individual's life. In developmental dyslexia, all skills related to reading might be affected (e.g., reading comprehension, word recognition, spelling, and oral reading). Around 3-7\% of the population is affected by dyslexia (Peterson and Pennington 2012). Emotional disturbances are associated with dyslexia and are common during one's school age. Besides challenges in academic achievements, anxiety, depression, anger, low self-esteem and confidence, and behavioral issues are commonly reported (e.g., Boyes et al. 2016; Daderman et al. 2014; Mammarella et al. 2014; Parhiala et al. 2014). In fact, individuals diagnosed with developmental dyslexia are found to display three times more challenging behaviors compared with individuals without (Mugnaini et al. 2009). Also, an increased number of ADHD incidents were reported (Germanò et al. 2010; Margari et al. 2013). 
Coming to VEs, their value as educational tools is well established (Merchant et al. 2014). They offer safe and controllable settings in which knowledge is applied (Marshall, 2014), social skills can be practiced (e.g., self-care and self-protection) (Didehbani et al. 2016; Kalyvioti and Mikropoulos 2014), and emotions can be expressed (Lorenzo et al. 2016). Due to these advantages, VEs are used in special education for teaching new skills or for enhancing others, for behavioral modification, and for fostering the manifestation of appropriate behaviors in real life.

As for why VEs are considered effective in the context of special education, researchers have hypothesized that training in realistic VEs can foster the acquisition of skills as well as the transfer and application of these skills to real-life (Blume et al. 2017; Ke and Moon, 2018). In fact, realist VEs were found to produce equally good results with therapies exposing participants to real-life conditions, as both expose subjects to similar sensory stimuli such as visual impressions and sounds, eliciting similar psychological responses (Bohil et al. 2011). In this context, given that individuals with autism spectrum disorders (ASD) are visual learners, the intrinsic appeal of VEs in individuals with this impairment is easily explained (Mitchell et al. 2007). Another advantage of VEs is that they offer a safe environment in which one can learn how to cope with emotions, by experimenting with various solutions without any real danger (Freina and Ott 2015). Not only that, but since in VEs there is no limit on how many times one can practice, the transfer of the learned skills or behaviors to real-life is significantly eased (Rizzo et al. 2011). This is probably the reason for using VEs, besides special education, for the treatment of conditions such as phobias, anxiety, depression, motor impairments, and stress management (Botella et al. 2017; Laver et al. 2017; Zeng et al. 2018). In the context of individuals with cognitive impairments (especially the ones with ASD), the opportunity of unlimited rehearsals removes their fear of making social mistakes and the anxiety they feel in their face-to-face interactions with others (Didehbani et al. 2016; Maskey et al. 2014). Quite logically, there is a positive impact on social interactions with peers, self-esteem, self-efficacy, self-image, and confidence, leading to the reduction of social isolation (Craig et al. 2016; Sakiz et al. 2015). Motivation is also a key feature of VEs. Individuals with special needs find the use of VEs a motivating as well as a rewarding experience (Didehbani et al. 2016; Ke and Moon 2018), thus, a cycle of continuous use and practice is initiated. The enjoyment they feel also adds to the above (Ke and Moon 2018; Lan et al. 2018).

Indeed, several studies used VEs for teaching functional living skills to students with special educational needs, diagnosed with an assortment of challenges such as motor or sensory impairments, learning and mental disorders, developmental impairments, and psychological or emotional disorders. For example, in children with Down Syndrome, VEs were used for improving their motor (Wuang et al. 2011) or language skills (Lan et al. 2018). Children with ASD were the target group in many studies utilizing VEs, in an effort to improve their social skills, as this is one of the core challenges they face (e.g., Stichter et al. 2014; Wang et al. 2017). The advancement of their problem-solving skills (Volioti et al. 2014) or the enhancement of their social and emotional skills (Craig et al. 2016), were the objectives of other studies. Students with ASD also face severe challenges in their everyday school life. As a result, VEs simulating school environments have been effectively used for enhancing communication and social perception skills (e.g., Ke and Moon 2018; Stichter et al. 2014), social understanding (Cheng et al. 
2015), how to make friends, confront abusers/bullies, and deal with social dilemmas (Didehbani et al. 2016). The development of communication skills was the goal of another VE in which typical students collaborated with students with ASD (Parsons 2015).

Students with ADHD or developmental dyslexia were the target group in far fewer studies using VEs. Nevertheless, with regard to such students, VEs also proved to be useful for easing their social difficulties (Shema-Shiratzky et al. 2018), improving their working memory, executive functions, and attention (e.g., Schwebel et al. 2008), and for reducing their behavioral issues (e.g., Wang and Reid 2011). To the best of the authors' knowledge, there are no studies in which VEs were used for demonstrating to these students how they are expected to function or behave in the school environment.

From this brief literature review, a number of essential conclusions can be drawn with regard to the needs of students with special educational needs in the context of the school environment: (i) studies mostly focused on examining how to provide an environment that can accommodate the academic and social needs of students with considerable impairments, fewer studies explicitly examined issues related to their adjustment in the school environment, (ii) the same applies when VEs were used, and (iii) even though there are studies that used VEs, targeted students with mild impairments, (i.e., ADHD or developmental dyslexia) and tried to teach or train them in life functional skills (e.g., social, communicational, and emotional skills), none were found that tried to illustrated specific and plain behaviors that are anticipated in school conditions. Given the above, the following research hypothesis was set forth:

Compared to videos, VEs have a more positive impact on the functional skills and behaviors related to the school environment of students with ADHD or developmental dyslexia, displaying challenging behaviors.

\section{Method}

\section{Research design}

A single-subject design with a baseline and an intervention phase (A-B design) was employed. An advantage of this type of research is that participants serve as their own controls. During the baseline phase (A-phase), data are collected multiple times. When stability is reached (meaning that the data do not fluctuate much), the treatment is introduced (intervention, B-phase) and another set of data collection follows. Conclusions can be drawn by examining changes in level or trend in the dependent variable (i.e., behaviors/performances during the A-phase are contrasted with behaviors/performances that occurred during or after the B-phase) (Engel and Schutt 2012; Wong 2010). Probably the most significant advantage of the A-B design is that it does not require large sample sizes. Research can be conducted with just one subject (thus, the term "singlesubject") or, typically, with three to eight subjects (Horner et al. 2012). This is very useful for research in special education, as in this type of research large sample sizes are almost impossible to achieve. Indeed, many argued that it constitutes the most feasible type of experimental design for individuals with impairments (e.g., Engel and Schutt 2012; Parker et al. 2008). Given that the study sought to compare two tools (VEs and videos), the A-B design was applied twice (discretely for each tool). 


\section{Participants}

As already mentioned, the target group was students diagnosed with ADHD or developmental dyslexia. Sample selection was probably the most significant challenge the study faced, as the inclusion of students with two different attentional, social, emotional, and learning impairments dictated the application of a rather extensive set of criteria for the proper selection of participants. The overall objective was to achieve a sample that included students diagnosed with the above impairments but, at the same time, to face considerable issues in school as a result of their limited functional skills and socially unacceptable behaviors. Not only that, but given that VEs were to be compared with videos, this necessitated the formation of two groups of students. Thus, a second concern was to form two as-much-as-possible equal groups. In order to properly recruit students, an initial set of selection criteria was applied. Students should: (i) be of similar age, (ii) have similar socioeconomic backgrounds, (iii) not have sensory or motor impairments, (iv) attend public mainstream schools, (v) have been formally diagnosed with ADHD or developmental dyslexia by a public assessing institution and in accordance to ICD-10 version 2016 (International Statistical Classification of Diseases and Related Health Problems 2016), (vi) be within the normal range of mental abilities (as assessed by the Greek version of Wechsler Intelligence Scale for Children), and (vii) display challenging behaviors and their school-related skills to be dysfunctional, rendering their adjustment to the school environment challenging.

A round of visits to schools in Athens, Greece, resulted in the initial selection of forty-two students. As the most important selection criterion was students to present severe (or at least noticeable) challenges in their functional skills regarding the school environment and to display challenging behaviors, the shortlisted students were then observed for a period of three months (two observations per week) and their teachers were interviewed. Besides assessing the extent of the issues these students faced, an additional objective of both the interviews and the observations was to establish that these issues uniformly affected most and not just a narrow range of in-school activities and tasks that the students had to perform on a daily basis. As a result, sixteen students (eight boys and eight girls, aged 8 to 9) were finally selected and were split into two groups as presented in Table 1 . Students 1 to 8 were assigned to Group1 (videos) and students 9 to 16 were assigned to Group2 (VE).

The following measures were taken in order to comply with the rules for conducting research with minors: (i) approval from the University's ethical committee was sought and granted, (ii) access to students' school performance, psychological evaluations, and diagnoses was granted by their parents and (iii) the schools' headmasters and teachers were informed of the study's objectives and procedures and their consent was granted.

\section{Materials}

As the study's theme was behaviors/skills in the school environment, one has to reflect on what constitutes a school environment. It can be supported that students have to function properly in the classroom (i.e., during lessons), in the schoolyard (i.e., during breaks and when playing), and during an event (i.e., a school play, a speech, and a ceremony). The above conditions, that require certain skills/behaviors, provided the basis for the design of the VE, which was developed by the authors using Opensimulator (http://opensimulator.org/). Following its development and testing, it was installed in 
Table 1 The study's participants

\begin{tabular}{|c|c|c|}
\hline Subjects & Classification/diagnosis* & Notes/behavioral related symptoms \\
\hline 1 and 9 & $\begin{array}{l}\text { F90.0, Disturbance of activity } \\
\text { and attention/ADHD }\end{array}$ & $\begin{array}{l}\text { Severe distraction, lack of functional attentional focus, } \\
\text { limited manifestation of expected social behaviors, } \\
\text { denial to comply with rules, responds with anger and } \\
\text { verbal violence when instructed to follow rules }\end{array}$ \\
\hline 2 and 10 & $\begin{array}{l}\text { F90.0, Disturbance of activity } \\
\text { and attention/ADHD }\end{array}$ & $\begin{array}{l}\text { Introversion, generalized weakness in social interactions, } \\
\text { unable to follow simple rules, indifferent to social } \\
\text { conventions, disorganized, verbally violent }\end{array}$ \\
\hline 3 and 11 & $\begin{array}{l}\text { F90.0, Disturbance of activity } \\
\text { and attention/ADHD }\end{array}$ & $\begin{array}{l}\text { Intensively hyperactive and impulsive, failure to manifest } \\
\text { the desired behaviors in their appropriate contexts, often } \\
\text { engages in inappropriate behaviors, verbally violent }\end{array}$ \\
\hline 4 and 12 & $\begin{array}{l}\text { F81.0, Specific reading } \\
\text { disorder/developmental dyslexia }\end{array}$ & $\begin{array}{l}\text { Hardly focuses on lessons, apparent indifference to } \\
\text { social conventions, ignorance of acceptable behaviors, } \\
\text { constant denial to comply with rules }\end{array}$ \\
\hline 5 and 13 & $\begin{array}{l}\text { F81.0, Specific reading } \\
\text { disorder/developmental } \\
\text { dyslexia }\end{array}$ & $\begin{array}{l}\text { severe concentration difficulties, outbursts of anger } \\
\text { and denial, often gets involved in fights with classmates } \\
\text { (verbal and physical), denial to comply with rules, often } \\
\text { engages in socially unacceptable activities }\end{array}$ \\
\hline 6 and 14 & $\begin{array}{l}\text { F81.0, Specific reading } \\
\text { disorder/ developmental } \\
\text { dyslexia }\end{array}$ & $\begin{array}{l}\text { Introversion, low self-esteem, limited repertoire of } \\
\text { attitudes and skills, often bullied but responds with } \\
\text { outbursts of anger, physical, and verbal violence }\end{array}$ \\
\hline 7 and 15 & $\begin{array}{l}\text { F90.0, Disturbance of activity } \\
\text { and attention/ADHD }\end{array}$ & $\begin{array}{l}\text { Severe behavioral issues, trouble following rules, } \\
\text { aggressiveness, often gets involved in fights with } \\
\text { classmates (verbal and physical), indifference to } \\
\text { social conventions }\end{array}$ \\
\hline 8 and 16 & $\begin{array}{l}\text { F90.0, Disturbance of activity } \\
\text { and attention/ADHD }\end{array}$ & $\begin{array}{l}\text { Impulsiveness, engagement in inappropriate } \\
\text { behaviors, lack of functional attentional focus, } \\
\text { responds with anger when instructed to follow rules, } \\
\text { often violent when playing with classmates }\end{array}$ \\
\hline
\end{tabular}

*Classification and diagnosis according to the Greek system for assessing students with special educational needs and to ICD-10 version 2016 (International Statistical Classification of Diseases and Related Health Problems 2016). Further details for the number of acceptable/desirable behaviors and functional skills of the participating students are provided in Table 4, first column—baseline phase

laptops as a stand-alone application. In essence, the VE represented a fictional school complex with classrooms, an assembly hall, and a schoolyard (Fig. 1) while the participating students, using their avatars, could freely explore it (Fig. 2). Details were added for making the VE more realistic. For example, most doors and lockers could be opened, bells were ringing, and sounds, commonly heard in a school, were recorded and auto-played. Basic interactions (e.g., the controls for playing sounds, displaying images, and opening or closing doors) were implemented using programming scripts.

Though the VE was rather minimalistic in its design, it was populated with several types of non-playable characters (NPCs) who acted either as students or as teachers. The programming of these puppeteered characters was a rather laborious task. That is because NPCs were programmed to follow pre-defined paths, change their animation sequences, and converse with each other, in order to demonstrate how one is supposed to behave during lessons, breaks, and school events. Moreover, as students while exploring the VE could accidentally avoid going to areas of interest, certain NPCs, around four to six in each condition/area of the VE, could "sense" the proximity of an avatar, follow it, and prompt students to navigate their avatars where the other NPCs were demonstrating the desired behaviors. Finally, in each area of the VE, a "teacher" NPC was placed. The role of these NPCs was quite important, as they partially substituted the real teacher. They could greet students and could converse with them (through text), responding to a limited set of 


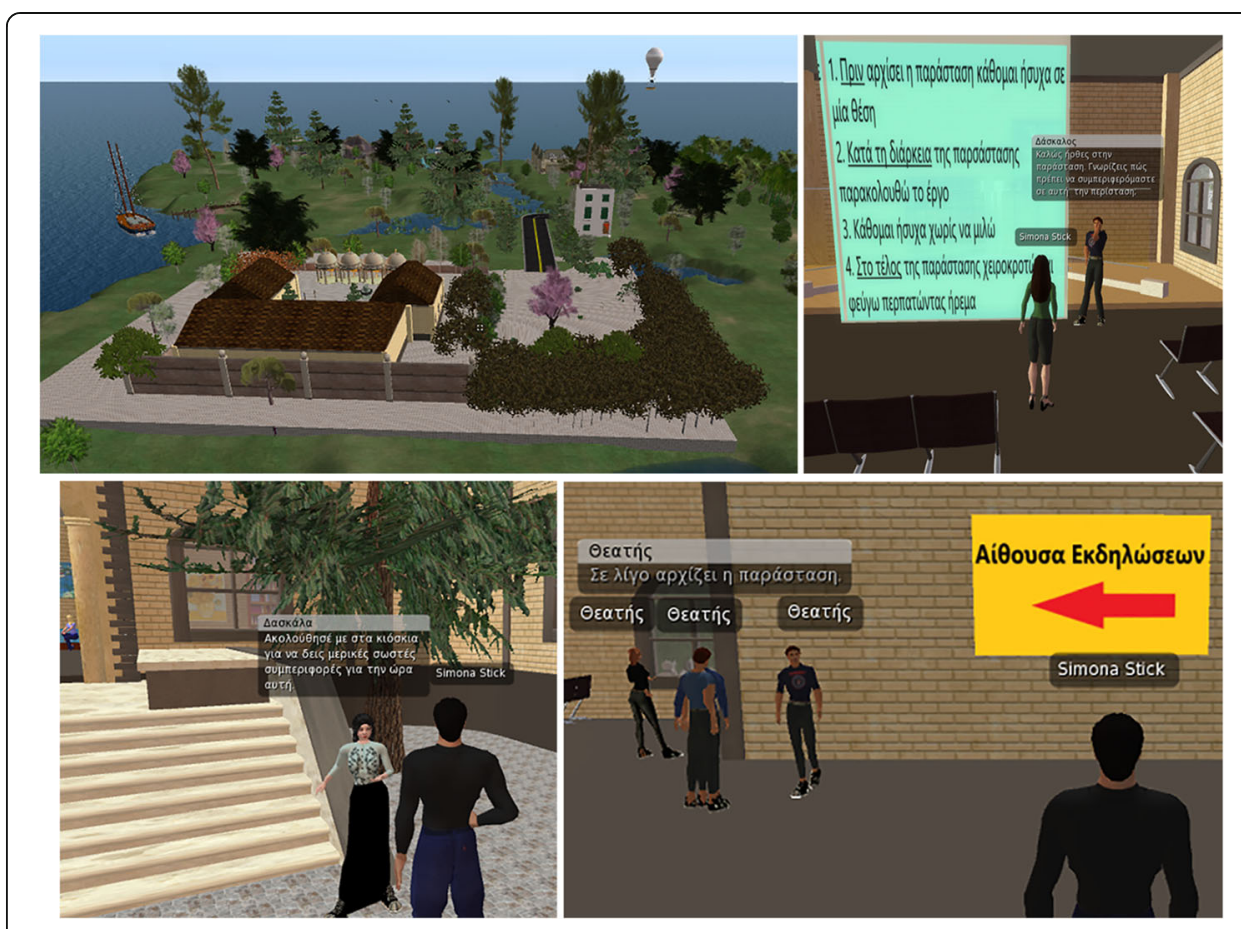

Fig. 1 Screenshots from the application

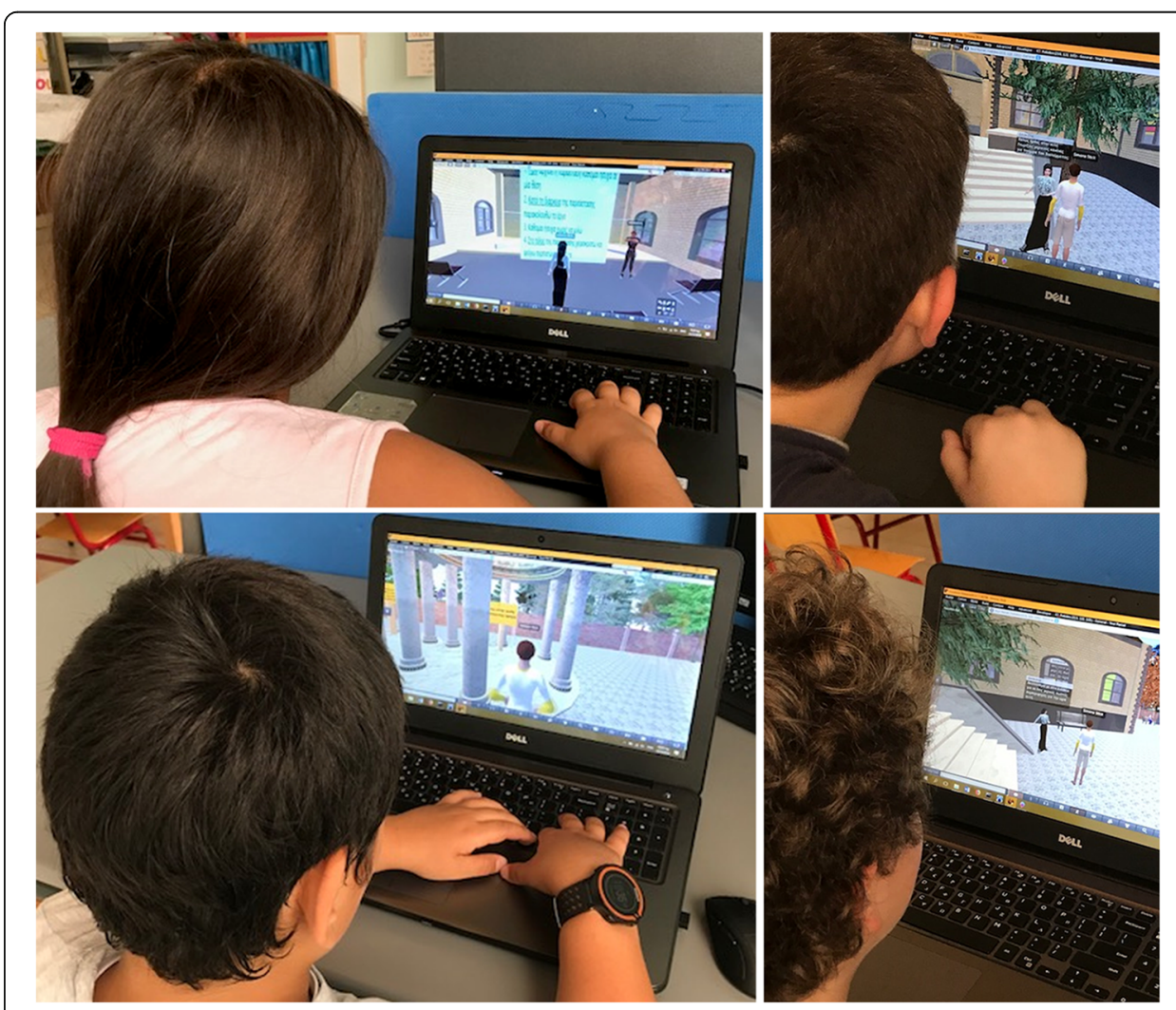

Fig. 2 Screenshots from the sessions 
inquiries. More importantly, following the naturalistic intervention principle (Rao et al. 2008), they could prompt students (verbally and non-verbally through animation sequences and postures), supplementing the naturalistic prompting, tasks, and scenarios presented by the teacher (see "Procedure" section). For example, their prompting ranged from repeating a request or question, to instructive or modeling cueing (using phrases like "I think that..." or "Let me explain/show you..."). An interesting aspect of the VE was that the NPCs were intentionally not programmed to correct their paths or animations when the user blocked them or pushed them around. Consequently, students could cause havoc to the VE; in essence, they could see the consequences of "inappropriate" behaviors. Finally, media screens (presenting videos, texts, and images) were placed in each area providing further details regarding the desired behaviors.

Three short videos (ten to fifteen minutes each) were filmed at a school (with real teachers and students). Scenarios (including dialogues) were written, for guiding students and teachers on how to act. The first part of these videos presented challenging situations/ behaviors in the three conditions (during lessons, breaks, and school events), while the second half illustrated how students were supposed to behave/function during the above conditions. For example, in a scene, a student was constantly harassing the student sitting right in front of him. In the first part, after a while, the second student retaliated and a quarrel started, while both ignored their teacher's efforts to stop them. In the second part, the second student instead of striking back decided to raise his hand and call for the teacher's help. Although these scenarios might be considered a bit unsophisticated, the age of the target group had to be taken into account (ages eight to nine), as well as the necessity to clearly present the challenging situations. Several shootings of a scene were required for finalizing it, because student-actors tended to overact their roles, reducing the believability of the situation they were trying to illustrate. As in the VE, the teachers acted as guides and explained which behaviors were wrong or right and why. For that matter, several additional scenes were recorded with just the teachers and were added during the video editing process. Finally, as in the videos the principles of observational learning (Miltenberger and Charlop 2015) were applied; a 3- to 5-s pause was added to certain key scenes. The objective was the teacher/researcher to be able to draw the participant's attention on what was about to happen (e.g., when a student in the video was about to misbehave).

\section{Procedure}

The single-variable rule in A-B designs recommends that, following the baseline phase, only one variable can be introduced and studied during the intervention phase. After this cycle is complete, another variable can be introduced (McMillan, 2004). Consequently, the project was organized as follows: (i) the baseline was established by observing the participating students for a period of two weeks (two observation sessions per week, each observation lasting for the whole duration of the school day), (ii) one condition was introduced to students (either using the VE or the videos), and (iii) intervention observations were conducted, again, for a period of two weeks. The above procedure was repeated three times as there were three conditions.

Each condition was administered during a 2-h session, on an individualized basis (one session per student). The teaching method utilized video-modeling techniques (as presented in the "Introduction" section) as well as teaching guidelines frequently applied in special education (Ashman and Conway 2017): (i) the objectives to be explicitly 
stated, (ii) the learning material to be gradually presented in small and understandable segments, (iii) the teacher to oversee the whole process, drawing students' attention on what is relevant, and (iv) the teacher to encourage the display of the desired skills/behaviors. In detail, the teaching method was as follows:

- At the beginning of the session, the researcher welcomed the student, discussed and asked questions in order to establish what he/she already knew for the given condition and the behaviors/skills he/she was supposed to exhibit.

- Using a laptop, depending on the group the student belonged to (video group or VE group), either the relevant video was played or the student entered the VE's area in which the given condition was simulated. If the latter was the case, the student could follow the teacher-NPC, watch the NPCs interact, and read, at will, the media screens. As already mentioned, the student could also intervene in such a way so that the NPCs to stop functioning properly. In this case, the VE was reset and rerun.

- After the end of the video or after the VE was explored for at least fifteen minutes, the researcher and the student engaged in a discussion, in order to develop an outline of what the latter understood. The researcher summarized key-points and draw the student's attention to them. These key-points are presented in the "Instrument" section.

- A second round of video watching or use of the VE was the next step. During this part, either the researcher or the student could pause the video or stop exploring the VE and discuss the key-points established in the previous step.

- A final round of discussions followed. This time, a "What you have to do if..." game was played. The researcher presented hypothetical situations (related to the condition that was the session's theme). For example, the researcher presented a situation in which a football game in the schoolyard went terribly wrong because a student took the ball and refused to give it back (or constantly made hard faults). The participating student was then asked to "act" how he/she would behave or what would his/her responses might be. He/she could also search the video or go to the area of the VE in which a similar situation was presented, and elaborate even further on the reasoning behind his/her course of actions.

- If necessary, the last two steps were repeated.

\section{Instrument}

An observation protocol was used for data collection purposes. This protocol was initially assembled on the basis of the finding of a previous study (Cheng et al. 2015). It was then refined and extended during the 3-month period prior to the beginning of the project, in which students were observed for possible inclusion to the project. Out of the challenging behaviors/functional skills that were noted during this period, the twelve most commonly manifested were finally selected. Table 2 presents these behaviors for each condition (Condition $\mathrm{A}=$ during breaks, Condition $\mathrm{B}=$ during lessons, and Condition $\mathrm{C}=$ during a school event).

Observational data (the number of times the desired behavior manifested) were collected simultaneously by two individuals (one teacher and one researcher) in both the study's baseline and intervention phase. The two raters were trained prior to the beginning of the project 
Table 2 Functional skills and behaviors for the three conditions (during breaks, lessons, and school events)

\begin{tabular}{ll}
\hline Condition & Skills/behaviors \\
\hline $\begin{array}{l}\text { A. Functional skills/behaviors during } \\
\text { breaks }\end{array}$ & I walk calmly in the schoolyard. \\
& I play with my schoolmates following the rules of our game. \\
& If I have a disagreement with my classmates, I talk to them about it. \\
& If I can't find a solution to the disagreement, I ask for the teachers' \\
& help.
\end{tabular}

(by observing the behavior of students without impairments) and during the baseline phase. The consistency among them was assessed using Cohen's kappa coefficient. The interrater reliability using the Kappa coefficient of agreement was found to be very good $[\kappa=.90, p<$ $.001,95 \%$ CI (.88, .92)] (Landis and Koch 1977).

\section{Results analysis}

For analyzing the data, the raters' observations in each observation session and for each participant were averaged. The averages were then summed in order to compare the results of the baseline and intervention phases. Table 3 presents descriptive statistics for both groups, while Table 4 presents the results in detail. Moreover, Fig. 3 is a graphical illustration of both groups' cumulative observations. A prerequisite of A-B designs is to achieve stability of the results during the baseline phase, before proceeding to the intervention phase. This requirement was met, as it can be inferred from Table 4 and Fig. 3. Thus, changes in the intervention phase can be attributed to the intervention per se. Indeed, considerable positive changes can be noted in all students, in all three conditions, and in both groups (see Table 3).

Condition $\mathrm{A}=$ during breaks; Condition $\mathrm{B}=$ during lessons; Condition $\mathrm{C}=$ during a school event

For examining whether the differences between the two groups, as illustrated in the above tables and figure, were statistically significant, one-way ANOVA tests were

Table 3 Means and standard deviations per group and per condition

\begin{tabular}{|c|c|c|c|c|c|c|c|}
\hline & & Condi & & Condi & & Condi & \\
\hline & & M & $S D$ & M & $S D$ & M & $S D$ \\
\hline Baseline phase observations & Group1 & 19.31 & 5.15 & 18.88 & 6.60 & 23.19 & 8.03 \\
\hline & Group2 & 20.13 & 5.26 & 19.25 & 6.77 & 22.75 & 6.47 \\
\hline Intervention phase observations & Group1 & 28.75 & 4.73 & 30.19 & 7.32 & 34.69 & 7.90 \\
\hline & Group2 & 37.13 & 7.18 & 40.13 & 7.06 & 44.44 & 3.81 \\
\hline
\end{tabular}


Table 4 The number of acceptable behaviors per observation session and per participant

\begin{tabular}{|c|c|c|c|c|c|c|c|c|c|}
\hline \multirow[t]{3}{*}{ Subject } & \multirow[t]{3}{*}{ Condition } & \multicolumn{8}{|c|}{ Observation session } \\
\hline & & \multicolumn{4}{|c|}{ Baseline phase } & \multicolumn{4}{|c|}{ Intervention phase } \\
\hline & & 1 & 2 & 3 & 4 & 5 & 6 & 7 & 8 \\
\hline \multicolumn{10}{|c|}{ Group1-video } \\
\hline \multirow[t]{3}{*}{1} & A & 6 & 6.5 & 5.5 & 5.5 & 6.5 & 6 & 6.5 & 6.5 \\
\hline & B & 4.5 & 3.5 & 3.5 & 3.5 & 5.5 & 5.5 & 5.5 & 5.5 \\
\hline & C & 5.5 & 5.5 & 5 & 5.5 & 7.5 & 7.5 & 8 & 7.5 \\
\hline \multirow[t]{3}{*}{2} & A & 3.5 & 3.5 & 4 & 3.5 & 6.5 & 6 & 6.5 & 6.5 \\
\hline & B & 2.5 & 2.5 & 3 & 2.5 & 5.5 & 5.5 & 5.5 & 5.5 \\
\hline & C & 2.5 & 3.5 & 2.5 & 2.5 & 5.5 & 4.5 & 4.5 & 4.5 \\
\hline \multirow[t]{3}{*}{3} & A & 3.5 & 3.5 & 4.5 & 3.5 & 5.5 & 5.5 & 5.5 & 5.5 \\
\hline & B & 6.5 & 6.5 & 6 & 5.5 & 7 & 7.5 & 7 & 7 \\
\hline & C & 6.5 & 7.5 & 7 & 6.5 & 9.5 & 10 & 10 & 10 \\
\hline \multirow[t]{3}{*}{4} & A & 7 & 7.5 & 6.5 & 7 & 7.5 & 7.5 & 7.5 & 7.5 \\
\hline & B & 4.5 & 5.5 & 4.5 & 4.5 & 7.5 & 7.5 & 7.5 & 7.5 \\
\hline & $C$ & 4.5 & 4.5 & 4.5 & 4 & 9.5 & 9 & 9.5 & 9.5 \\
\hline \multirow[t]{3}{*}{5} & A & 3.5 & 3.5 & 3 & 3.5 & 6 & 6.5 & 6.5 & 6.5 \\
\hline & B & 2.5 & 2.5 & 2.5 & 2.5 & 6.5 & 6 & 5.5 & 6 \\
\hline & C & 4 & 4 & 3.5 & 4.5 & 7.5 & 7 & 7.5 & 7.5 \\
\hline \multirow[t]{3}{*}{6} & A & 5.5 & 5.5 & 6 & 5.5 & 8.5 & 8.5 & 8.5 & 8.5 \\
\hline & B & 5 & 6 & 5.5 & 5.5 & 10 & 10 & 9.5 & 9.5 \\
\hline & $C$ & 8 & 7.5 & 7.5 & 8.5 & 10 & 10.5 & 10.5 & 10.5 \\
\hline \multirow[t]{3}{*}{7} & A & 5 & 4.5 & 5.5 & 5.5 & 8.5 & 8.5 & 8 & 8.5 \\
\hline & B & 5.5 & 5 & 5.5 & 5.5 & 9.5 & 9.5 & 9.5 & 9.5 \\
\hline & $C$ & 6.5 & 6.5 & 6.5 & 7 & 9.5 & 9.5 & 9 & 9.5 \\
\hline \multirow[t]{3}{*}{8} & A & 3.5 & 4.5 & 4.5 & 4.5 & 8.5 & 8.5 & 8.5 & 8.5 \\
\hline & B & 6.5 & 7 & 7.5 & 7.5 & 9.5 & 9.5 & 9.5 & 9.5 \\
\hline & $C$ & 8.5 & 9 & 8 & 8.5 & 10.5 & 10.5 & 10.5 & 11 \\
\hline \multicolumn{10}{|c|}{ Group2-VE } \\
\hline \multirow[t]{3}{*}{9} & A & 4.5 & 6.5 & 6 & 6 & 8.5 & 8.5 & 6.5 & 8.5 \\
\hline & B & 4.5 & 3.5 & 4 & 4.5 & 8.5 & 8.5 & 8.5 & 7.5 \\
\hline & C & 5.5 & 5.5 & 5.5 & 5.5 & 10.5 & 10 & 10.5 & 9.5 \\
\hline \multirow[t]{3}{*}{10} & A & 3.5 & 3.5 & 3.5 & 3.5 & 10 & 9.5 & 8.5 & 9 \\
\hline & B & 2.5 & 2.5 & 2.5 & 2.5 & 9.5 & 9 & 9.5 & 9.5 \\
\hline & $C$ & 3 & 3 & 3 & 3 & 10 & 9.5 & 9.5 & 9.5 \\
\hline \multirow[t]{3}{*}{11} & A & 4.5 & 4.5 & 4.5 & 4.5 & 7.5 & 7.5 & 7.5 & 7.5 \\
\hline & B & 6.5 & 6.5 & 5.5 & 5.5 & 10.5 & 10 & 8 & 7.5 \\
\hline & $C$ & 8.5 & 8 & 7 & 5.5 & 11.5 & 11 & 11.5 & 10.5 \\
\hline \multirow[t]{3}{*}{12} & A & 7.5 & 7.5 & 7.5 & 7.5 & 9.5 & 9 & 8 & 8 \\
\hline & B & 5 & 5 & 4.5 & 4.5 & 8.5 & 7.5 & 8 & 7.5 \\
\hline & $C$ & 4.5 & 4.5 & 4.5 & 4.5 & 12.5 & 11.5 & 12 & 12 \\
\hline \multirow[t]{3}{*}{13} & $A$ & 3.5 & 3.5 & 3.5 & 3.5 & 7.5 & 8 & 8.5 & 8 \\
\hline & B & 2.5 & 2.5 & 2.5 & 2.5 & 10.5 & 10.5 & 8.5 & 9.5 \\
\hline & C & 4.5 & 4.5 & 4.5 & 4.5 & 10.5 & 10.5 & 10 & 10.5 \\
\hline 14 & A & 5.5 & 5 & 5.5 & 5.5 & 10 & 9.5 & 9.5 & 8 \\
\hline
\end{tabular}


Table 4 The number of acceptable behaviors per observation session and per participant (Continued)

\begin{tabular}{|c|c|c|c|c|c|c|c|c|c|}
\hline \multirow[t]{3}{*}{ Subject } & \multirow[t]{3}{*}{ Condition } & \multicolumn{8}{|c|}{ Observation session } \\
\hline & & \multicolumn{4}{|c|}{ Baseline phase } & \multicolumn{4}{|c|}{ Intervention phase } \\
\hline & & 1 & 2 & 3 & 4 & 5 & 6 & 7 & 8 \\
\hline & B & 5 & 6 & 5.5 & 6 & 11 & 11.5 & 11.5 & 11.5 \\
\hline & C & 7.5 & 6.5 & 7.5 & 8 & 12.5 & 12 & 11.5 & 12 \\
\hline \multirow[t]{3}{*}{15} & A & 5 & 5 & 6 & 6.5 & 12.5 & 13.5 & 13 & 13 \\
\hline & B & 5.5 & 5.5 & 6 & 6 & 13 & 12.5 & 12.5 & 12.5 \\
\hline & C & 5 & 6 & 6.5 & 6.5 & 12 & 11.5 & 11.5 & 13 \\
\hline \multirow[t]{3}{*}{16} & A & 4 & 4.5 & 4.5 & 4.5 & 11 & 10.5 & 9.5 & 11.5 \\
\hline & B & 6.5 & 7 & 7.5 & 8 & 11.5 & 11.5 & 12.5 & 12.5 \\
\hline & C & 6.5 & 8.5 & 7.5 & 7 & 12.5 & 11 & 11.5 & 11.5 \\
\hline
\end{tabular}

The numbers in cells are the average of the two raters' number of observations

conducted for all three conditions. The data were suitable for this type of testing as the two groups had an equal number of participants, there were no outliers, the data distribution was normal, and the homogeneity of variance was not violated. It was found that: (i) in the baseline phase, the two groups had no statistically significant differences and (ii) in the intervention phase, Group2 outperformed Group1 with statistically significant differences in all three conditions (Table 5). Given that, the study's hypothesis was confirmed; compared to the use of videos, the use of VEs can improve significantly more the functional skills and behaviors related to the school environment of students with ADHD or developmental dyslexia.

\section{Discussion}

The study examined whether a VE can help students with ADHD or developmental dyslexia to further develop their functional living skills related to the school environment. Twelve such behaviors/skills were selected (see Table 2), falling into three

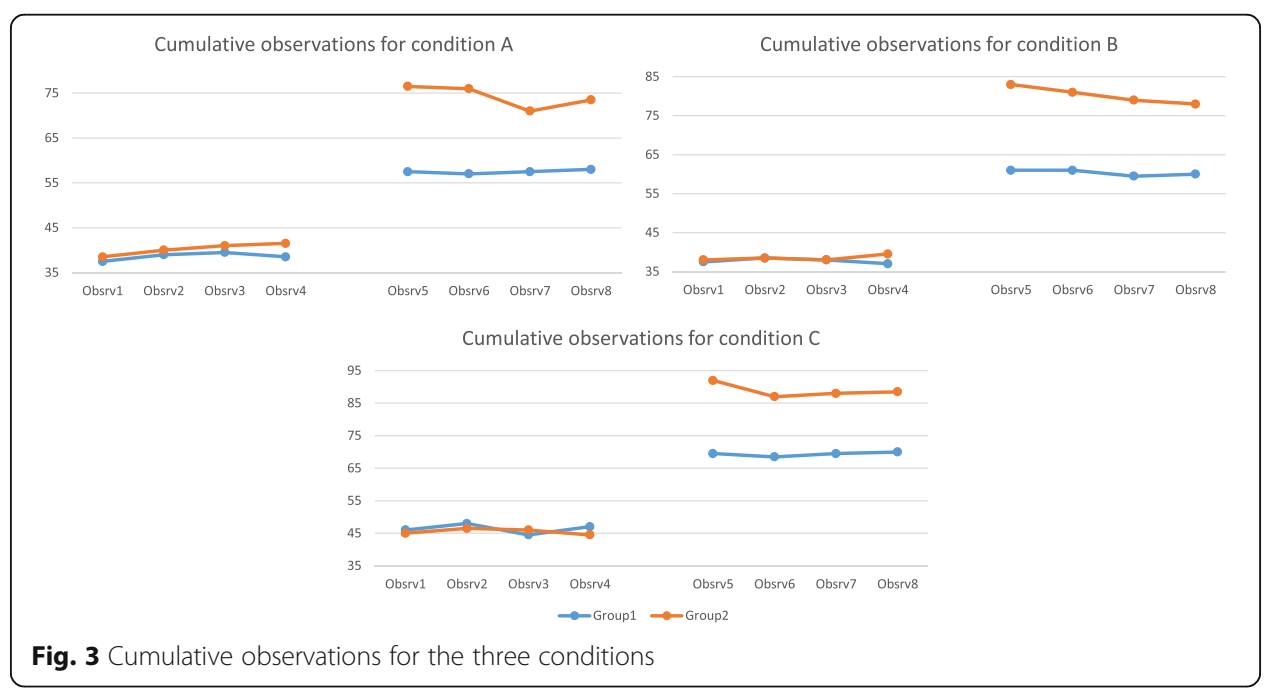


Table $\mathbf{5}$ Results of one-way ANOVA tests

\begin{tabular}{|c|c|c|c|c|c|c|}
\hline & \multicolumn{2}{|c|}{ Condition A } & \multicolumn{2}{|c|}{ Condition B } & \multicolumn{2}{|c|}{ Condition C } \\
\hline & $F(1,14)$ & $p$ & $F(1,14)$ & $p$ & $F(1,14)$ & $p$ \\
\hline Baseline phase & 0.097 & .760 & 0.013 & .912 & 0.014 & .906 \\
\hline Intervention phase & 7.599 & .015 & 7.640 & .015 & 9.882 & .007 \\
\hline
\end{tabular}

conditions (i.e., during lessons, during breaks, and during a school event). Three 2-h sessions were conducted with the eight participating students and data were compared with another group of eight students who used videos. The results, as presented in the preceding section, demonstrated that all students (in both groups) significantly increased the number of the desired behaviors/skills they were able to display in real school conditions. In this respect, it can be supported that both tools (videos and VEs) were effective. Then again, further analysis of the results provided evidence that the VE was more effective than videos. Thus, the study's findings provide additional support to previous research which suggested that VEs do contribute to the improvement of behaviors/skills related to the school environment (e.g., Didehbani et al. 2016; Ke and Moon 2018; Lan et al. 2018; Stichter et al. 2014; Wang et al. 2017). On the other hand, most of the above-cited studies targeted children with ASD. Therefore, the study's findings expand the relevant literature, by providing support to the view that VEs are also effective when the target group is students with ADHD or developmental dyslexia.

The results can be attributed to the teaching method that was followed, as well as to the VE per se. As far as students with special educational needs are concerned, VEs can provide controlled, realistic, secure, and rich environments, in which it is easier to transfer the behaviors they have learned in the VEs to real-life conditions (Blume et al. 2017; Freina and Ott 2015; Vasquez III et al. 2017). Second, it is suggested that the skills/behaviors learned through VEs have to be linked with skills/behaviors applicable to students' everyday life, preferably with ones that can be practiced relatively promptly and regularly (Rizzo et al. 2011), so as students to be able to generalize them in similar circumstances (Blume et al. 2017; Freina and Ott 2015; Vasquez III et al. 2017). The above suggestion was followed, almost word for word, in the present study. Students explored the VE, encountered plausible/realistic conditions (related to ones they encounter in their daily school life), they were able to see how they are expected to function, and they were asked to apply and demonstrate the target behaviors/skills.

Motivation is one of VEs' key advantages. Students with special educational needs are motivated to be actively engaged in the learning process, resulting in knowledge gains and better understanding of concepts (Blume et al. 2017; Didehbani et al. 2016; Freina and Ott 2015; Vasquez III et al. 2017), followed by the senses of fulfillment and satisfaction (Rix et al. 2009). Self-esteem, self-image, and confidence are positively influenced, as students can see that the above lead to an advancement of their social, emotional, and behavioral status in school (Craig et al. 2016; Sakiz et al. 2015). Confidence then leads to independence, encouraging them to manifest more behaviors that are acceptable from their peers and teachers (Lan et al. 2018). On the basis of the study's results, this chain of knowledge-behavior transformations was confirmed. Indeed, from Table 3 and Fig. 3 it is clear that during the baseline phase students manifested a limited number of acceptable behaviors (in all three conditions). Contrary to that, the results during the intervention phase indicated that the number of desired 
behaviors was almost doubled in the VE group (compared to a 50\% increase in the videos group). Thus, it is quite safe to assume that what was practiced in the VE and discussed with the researcher/teacher was "transformed" into actual skills/behaviors. More importantly, as data were recorded multiple times during a span of two weeks, this indicates that, up to a certain point, students mastered these skills/behaviors and that they became more confident.

\section{Implications for research and practice}

The study's implications for research are related to the research question which sought to examine. Indeed, the relevant literature regarding the use of VEs in special education, while not limited, is rather fragmented across diverse disciplines and settings. What is more, research on children presenting rather mild attentional, social, emotional, and learning impairments (e.g., with ADHD or developmental dyslexia) are not the focus of many studies, as researchers have paid more attention to more severe impairments, such as ASD. The study at hand chose to examine the effects of VEs on students with ADHD and dyslexia, displaying challenging behaviors. In addition, the content (and the context) of the VE was related to the school environment. Again, this research path is relatively uncharted. On the basis of the results, it can be supported that the use of VEs for the behavioral modification of children with learning, attentional, behavioral, and emotional impairments, is a research path worth exploring.

The study's findings have also implications for the educators in special education, as well as for the developers of VEs. The VE was developed by the authors. Although they were capable of developing such applications, they were by no means experts in this field. Given its simplicity, one might argue that the VE was amateurish and that its flaws might have had a negative impact on the results. Although these concerns are, up to a certain point, valid, one has also to take into account the fact that professionally developed VEs that could suit the study's needs are non-existent. Moreover, it is questionable whether a sufficient number of such applications can be professionally developed. Considering that students with special educational needs present a large variety of challenges and impairments, applications suitable for a set of issues are probably not suitable for another set. This is why Stichter et al. (2014) argued that applications developed by the special education teachers are better aligned with their students' needs. Thus, a plausible solution is software experts to equip educators with tools that make the whole process of developing VEs much more efficient and appealing to them (Scacchi 2012).

\section{Limitations and future work}

There are limitations to the study that bear mentioning but also provide avenues for future research. While the small sample size may raise concerns, it has to be stressed that it was more than adequate for an A-B research design. In addition, research in special education, in terms of sample sizes, has many restrictions, as the target population is smaller than the general one and one has to be extremely careful not to select cases that differ a lot from each other. Although all students in the sample displayed notable to severe behavioral issues related to the school environment, the inclusion of different types of attentional, social, emotional, and 
learning impairments might be viewed as a problem. Nevertheless, it has to be acknowledged that due to the above, the generalizability of the study's results is limited. The schools' timetables proved to be rather inflexible; the limited availability of time also limited the number of interventions that could be realized. Although the number of observations was enough for establishing the results' stability (and within the suggested number of observations for an A-B study), more of them would have increased the findings' credibility. Moreover, the long-term retention of behaviors and skills is unknown. Future research can target students from different age groups and with other special needs and compare the results. Interviews will allow an in-depth understanding of the impact of both videos and VEs. Finally, professionally developed VEs can also be used for examining whether there is a significant variation in the results.

\section{Conclusion}

In sum and considering both the aforementioned results and limitations, the study provided an idea about how VEs might deliver additional support to students with attentional, social, emotional, and learning impairments, in order to overcome the challenges they face in the school environment. What is more, the study makes a (small) contribution to the relevant literature, by providing evidence that, through the use of VEs, students with attentional, social, emotional, and learning impairments, can positively change their behaviors and acquire skills that, in turn, can be applied in reallife conditions. In conclusion, the study's findings might prove useful to researchers and educators in understanding and effectively utilizing VEs in special education.

Acknowledgments

Not applicable.

\section{Authors' contributions}

All authors contributed to the study equally, on the design, data collection, and analysis as well as writing the article. Please note that the authors hold the copyrights of all figures included in the manuscript; there is no need to obtain permission from other sources in order to reproduce these figures. All authors read and approved the final manuscript.

\footnotetext{
Authors' information

Dr. Emmanuel Fokides is an Assistant Professor in the Department of Primary School Education, University of the Aegean, Greece. His courses focus on the educational uses of emerging technologies, virtual reality, digital storytelling, augmented reality, and serious games. Since 1994, he is involved in a number of research projects regarding distance and lifelong learning and the educational uses of virtual and augmented reality. He is also the founder of the Emerging Technologies in Education initiative (ETiE). His work is published in several conference proceedings, chapters in edited books, and journals. He is also the co-author of two books.

Maria-loanna Chronopoulou holds master's degrees in Special Education and in New Technologies in Education. She serves as a special education teacher in public Greek schools, focusing on enhancing students' social, emotional, academic, and everyday functional living skills. She is involved in research projects examining how various ICT tools can differentiate the typical syllabus, enhance positive skills, and decrease nonfunctional or harmful behaviors of students with special needs.

Polyxeni Kaimara, MSc Developmental and Educational Psychologist, is a Ph.D. candidate in the Department of Audiovisual Arts of the Ionian University in Corfu, Greece. She holds a master's degree in Public Health, a Degree in Counseling and Guidance, a Certification of Adult Training and a Certification of Qualifications \& Vocational Guidance. She has teaching experience at the Western Macedonia University and Ionian University. She is working as a psychologist at an educational center for people with disabilities in Florina, Greece. She is the co-author of several papers and chapters. Her research interests focus on the design and evaluation of educational systems for special education and training, and the implementation of digital games aimed at designing programs for inclusive education.
}

Funding

Not applicable. 


\section{Competing interests}

The authors declare that they have no competing interests.

\section{Author details}

${ }^{1}$ Department of Primary Education, University of the Aegean, Rhodes, Greece. ${ }^{2}$ Department of Audio and Visual Arts, Ionian University, Corfu, Greece. ${ }^{3} 1$ Dimokratias str., 85132, Rhodes, Greece.

Received: 23 April 2019 Accepted: 8 November 2019

Published online: 04 December 2019

\section{References}

American Psychiatric Association. (2013). Diagnostic and statistical manual of mental disorders. BMC Med, 17, 133-137. https:// doi.org/10.1176/appi.books.9780890425596.

Ashman, A. F., \& Conway, R. N. (2017). Using cognitive methods in the classroom. Routledge. https://doi.org/10.4324/ 9781315271019.

Blandon, A. Y., Calkins, S. D., Grimm, K. J., Keane, S. P., \& O'Brien, M. (2010). Testing a developmental cascade model of emotional and social competence and early peer acceptance. Development and Psychopathology, 22(4), 737-748. https:// doi.org/10.1017/S0954579410000428.

Blume, F., Hudak, J., Dresler, T., Ehlis, A. C., Kühnhausen, J., Renner, T. J., \& Gawrilow, C. (2017). NIRS-based neurofeedback training in a virtual reality classroom for children with attention-deficit/hyperactivity disorder: study protocol for a randomized controlled trial. Trials, 18(1), 41. https://doi.org/10.1186/s13063-016-1769-3.

Bohil, C. J., Alicea, B., \& Biocca, F. A. (2011). Virtual reality in neuroscience research and therapy. Nature reviews neuroscience, 12(12), 752. https://doi.org/10.1038/nrn3122.

Botella, C., Fernández-Álvarez, J., Guillén, V., García-Palacios, A., \& Baños, R. (2017). Recent progress in virtual reality exposure therapy for phobias: a systematic review. Current Psychiatry Reports, 19(7), 42. https://doi.org/10.1007/s11920-017-0788-4.

Boyes, M. E., Leitao, S., Claessen, M., Badcock, N. A., \& Nayton, M. (2016). Why are reading difficulties associated with mental health problems? Dyslexia, 22(3), 263-266. https://doi.org/10.1002/dys.1531.

Cheng, Y., Huang, C. L., \& Yang, C. S. (2015). Using a 3D immersive virtual environment system to enhance social understanding and social skills for children with autism spectrum disorders. Focus on Autism and Other Developmental Disabilities, 30(4), 222-236. https://doi.org/10.1177/1088357615583473.

Craig, A. B., Brown, E. R., Upright, J., \& DeRosier, M. E. (2016). Enhancing children's social emotional functioning through virtual game-based delivery of social skills training. Journal of Child and Family Studies, 25(3), 959-968. https://doi.org/10.1007/ s10826-015-0274-8.

Daderman, A. M., Nilvang, K., \& Levander, S. (2014). "I dislike my body, I am unhappy, but my parents are not disappointed in me": Self-esteem in young women with dyslexia. Psychological Research Journal, 1(1), 50-58. https://doi.org/10.18552/aprj. v1i1.136.

Didehbani, N., Allen, T., Kandalaft, M., Krawczyk, D., \& Chapman, S. (2016). Virtual reality social cognition training for children with high functioning autism. Computers in Human Behavior, 62, 703-711. https://doi.org/10.1016/j.chb.2016.04.033.

Domitrovich, C. E., Cortes, R. C., \& Greenberg, M. T. (2007). Improving young children's social and emotional competence: A randomized trial of the preschool "PATHS" curriculum. The Journal of Primary Prevention, 28(2), 67-91. https://doi.org/10. 1007/s10935-007-0081-0.

Dyck, M. J., \& Piek, J. P. (2014). Developmental delays in children with ADHD. Journal of Attention Disorders, 18(5), 466-478. https://doi.org/10.1177/1087054712441832.

Engel, R. J., \& Schutt, R. K. (2012). The practice of research in social work. Thousand Oaks: Sage Publications.

Espelage, D. L., Rose, C. A., \& Polanin, J. R. (2016). Social-emotional learning program to promote prosocial and academic skills among middle school students with disabilities. Remedial and Special Education, 37(6), 323-332. https://doi.org/10.1177/ 0741932515627475.

Factor, P. I., Rosen, P. J., \& Reyes, R. A. (2016). The relation of poor emotional awareness and externalizing behavior among children with ADHD. Journal Of Attention Disorders, 20(2), 168-177. https://doi.org/10.1177/1087054713494005.

Faraone, S. V., Rostain, A. L., Blader, J., Busch, B., Childress, A. C., Connor, D. F., \& Newcorn, J. H. (2019). Practitioner Review: Emotional dysregulation in attention-deficit/hyperactivity disorder-implications for clinical recognition and intervention. Journal of Child Psychology and Psychiatry, 60(2), 133-150. https://doi.org/10.1111/jcpp.12899.

Fayyad, J., Sampson, N. A., Hwang, I., Adamowski, T., Aguilar-Gaxiola, S., Al-Hamzawi, A., et al. (2017). The descriptive epidemiology of DSM-IV Adult ADHD in the world health organization world mental health surveys. ADHD Attention Deficit and Hyperactivity Disorders, 9(1), 47-65. https://doi.org/10.1007/s12402-016-0208-3.

Freina, L., \& Ott, M. (2015). A literature review on Immersive Virtual Reality in education: State of the art and perspectives. elearning \& Software for Education, 1.

Garrote, A., Dessemontet, R. S., \& Opitz, E. M. (2017). Facilitating the social participation of pupils with special educational needs in mainstream schools: A review of school-based interventions. Educational Research Review, 20, 12-23. https://doi. org/10.1016/j.edurev.2016.11.001.

Germanò, E., Gagliano, A., \& Curatolo, P. (2010). Comorbidity of ADHD and dyslexia. Developmental Neuropsychology, 35(5), 475-493. https://doi.org/10.1080/87565641.2010.494748.

Hirsch, S. E., MacSuga-Gage, A. S., Ennis, R. P., Mathews, H. M., Rice, K., \& Marcus, K. (2019). Using videos to promote positive behavioral interventions and supports: A qualitative study. Journal of Special Education Technology, 0162643419836408. doi: https://doi.org/10.1177/0162643419836408

Horner, R. H., Swaminathan, H., Sugai, G., \& Smolkowski, K. (2012). Considerations for the systematic analysis and use of singlecase research. Education and Treatment of Children, 35(2), 269-290. https://doi.org/10.1353/etc.2012.0011.

International Statistical Classification of Diseases and Related Health Problems (2016). The International Classification of Diseases (ICD), version 2016. Retrieved from https://icd.who.int/browse10/2016/en

Kalyvioti, K., \& Mikropoulos, T. A. (2014). Virtual environments and dyslexia: A literature review. Procedia Computer Science, 27, 138-147. https://doi.org/10.1016/j.procs.2014.02.017. 
Kanfush, P. M., \& Jaffe, J. W. (2019). Using video modeling to teach a meal preparation task to individuals with a moderate intellectual disability. Education Research International, 2019. https://doi.org/10.1155/2019/1726719.

Ke, F., \& Moon, J. (2018). Virtual collaborative gaming as social skills training for high-functioning autistic children. British Journal of Educational Technology, 49(4), 728-741. https://doi.org/10.1111/bjet.12626.

Kellems, R. O., \& Edwards, S. (2016). Using video modeling and video prompting to teach core academic content to students with learning disabilities. Preventing School Failure: Alternative Education for Children and Youth, 60(3), 207-214. https://doi. org/10.1080/1045988x.2015.1067875.

Kennedy, M. J., \& Swain-Bradway, J. (2012). Rationale and recommended practices for using homegrown video to support school-wide positive behavioral interventions and supports. Beyond Behavior, 21(2), 20-29.

Lan, Y. J., Hsiao, I. Y., \& Shih, M. F. (2018). Effective learning design of game-based 3D virtual language learning environments for special education students. Journal of Educational Technology \& Society, 21(3).

Landis, J. R., \& Koch, G. G. (1977). The measurement of observer agreement for categorical data. Biometrics, 33, 159-174. https://doi.org/10.2307/2529310.

Laver, K. E., Lange, B., George, S., Deutsch, J. E., Saposnik, G., \& Crotty, M. (2017). Virtual reality for stroke rehabilitation. Cochrane Database of Systematic Reviews, 11. https://doi.org/10.1002/14651858.CD008349.pub4.

Lorenzo, G., Lledó, A., Pomares, J., Roig, R., \& Arnaiz, P. (2016). Bibliometric indicators in the study of Asperger syndrome between 1990 and 2014. Scientometrics, 109(1), 377-388. https://doi.org/10.1007/s11192-016-1975-5.

Mammarella, I., Ghisi, M., Bomba, M., Bottesi, G., Caviola, S., Broggi, F., \& Nacinovich, R. (2014). Anxiety and depression in children with nonverbal learning disabilities, reading disabilities, or typical development. Journal of Learning Disabilities, 49(2). https://doi.org/10.1177/0022219414529336.

Margari, L., Buttiglione, M., Craig, F., Cristella, A., de Giambattista, C., Matera, E., et al. (2013). Neuropsychopathological comorbidities in learning disorders. BMC Neurology, 13(198), 1-6. https://doi.org/10.1186/1471-2377-13-198.

Marshall, A. (2014). Sensemaking in Second Life. Procedia Technology, 13, 107-111. https://doi.org/10.1016/.protcy.2014.02.014.

Maskey, M., Lowry, J., Rodgers, J., McConachie, H., \& Parr, J. R. (2014). Reducing specific phobia/fear in young people with Autism Spectrum Disorders (ASDs) through a virtual reality environment intervention. PLoS One, 9(7), e100374. https://doi. org/10.1371/journal.pone.0100374.

Mason, R. A., Davis, H. S., Boles, M. B., \& Goodwyn, F. (2013). Efficacy of point-of-view video modeling: A meta-analysis. Remedial and Special Education, 34(6), 333-345. https://doi.org/10.1177/0741932513486298.

McMillan, J. H. (2004). Educational research: Fundamentals for the consumer (4th ed.). Boston: Allyn and Bacon.

McNiff, M. T., Maag, J. W., \& Peterson, R. L. (2019). Group Video Self-Modeling to Improve the Classroom Transition Speeds for Elementary Students. Journal of Positive Behavior Interventions, 21(2), 117-127. https://doi.org/10.1177/1098300718796788.

Merchant, Z., Goetz, E. T., Cifuentes, L., Keeney-Kennicutt, W., \& Davis, T. J. (2014). Effectiveness of virtual reality-based instruction on students' learning outcomes in K-12 and higher education: A meta-analysis. Computers \& Education, 70, 29-40. https://doi.org/10.1016/..compedu.2013.07.033.

Miltenberger, C. A., \& Charlop, M. H. (2015). The comparative effectiveness of portable video modeling vs. traditional video modeling interventions with children with autism spectrum disorders. Journal of Developmental and Physical disabilities, 27(3), 341-358. https://doi.org/10.1007/s10882-014-9416-y.

Mitchell, P., Parsons, S., \& Leonard, A. (2007). Using virtual environments for teaching social understanding to 6 adolescents with autistic spectrum disorders. Journal of Autism Development Disorders, 37, 589-600. https://doi.org/10.1007/s10803006-0189-8.

Mugnaini, D., Lassi, S., La Malfa, G., \& Albertini, G. (2009). Internalizing correlates of dyslexia. World Journal of Pediatrics, 5(4), 255-264. https://doi.org/10.1007/s12519-009-0049-7.

Nye, E., Gardner, F., Hansford, L., Edwards, V., Hayes, R., \& Ford, T. (2016). Classroom behaviour management strategies in response to problematic behaviours of primary school children with special educational needs: views of special educational needs coordinators. Emotional and Behavioural Difficulties, 21(1), 43-60. https://doi.org/10.1080/13632752. 2015.1120048

Office of Special Education and Rehabilitative Services (ED) (2015). 37th annual report to Congress on the implementation of the" Individuals with Disabilities Education Act," 2015. ERIC Clearinghouse.

Parhiala, P., Torppa, M., Eklund, K., Aro, T., Poikkeus, A., Heikkilä, R., \& Ahonen, T. (2014). Psychosocial functioning of children with and without dyslexia: A follow-up study from ages four to nine. Dyslexia, 21(3), 197-211. https://doi. org/10.1002/dys.1486.

Parker, A. T., Grimmett, E. S., \& Summers, S. (2008). Evidence-based communication practices for children with visual impairments and additional disabilities: An examination of single-subject design studies. Journal of Visual Impairment \& Blindness, 102(9), 540-552. https://doi.org/10.1177/0145482X0810200904.

Parsons, S. (2015). Learning to work together: designing a multi-user virtual reality game for social collaboration and perspective-taking for children with autism. International Journal of Child-Computer Interaction, 6, 28-38. https://doi.org/ 10.1016/j.jijcci.2015.12.002.

Peterson, R. L., \& Pennington, B. F. (2012). Developmental dyslexia. The Lancet, 379(9830), 1997-2007. https://doi.org/10.1016/ S0140-6736(12)60198-6.

Portman, M. E., Natapov, A., \& Fisher-Gewirtzman, D. (2015). To go where no man has gone before: Virtual reality in architecture, landscape architecture and environmental planning. Computers, Environment and Urban Systems, 54, 376384. https://doi.org/10.1016/j.compenvurbsys.2015.05.001.

Rao, P. A., Beidel, D. C., \& Murray, M. J. (2008). Social skills interventions for children with Asperger's syndrome or highfunctioning autism: A review and recommendations. Journal of Autism and Developmental Disorders, 38, 353-361. https:// doi.org/10.1007/s10803-007-0402-4.

Rix, J., Hall, K., Nind, M., Sheehy, K., \& Wearmouth, J. (2009). What pedagogical approaches can effectively include children with special educational needs in mainstream classrooms? A systematic literature review. Support for Learning, 24(2), 8694. https://doi.org/10.1111/j.1467-9604.2009.01404.x.

Rizzo, A., Parsons, T. D., Lange, B., Kenny, P., Buckwalter, J. G., Rothbaum, B... \& Reger, G. (2011). Virtual reality goes to war: A brief review of the future of military behavioral healthcare. Journal of Clinical Psychology in Medical Settings, 18(2), 176187. doi: https://doi.org/10.1007/s10880-011-9247-2 
Rose, R., Shevlin, M., Winter, E., \& O'Raw, P. (2015). Project IRIS, inclusive research in Irish schools. A longitudinal study of the experiences of and outcomes for pupils with special educational needs (SEN) in Irish schools. Trim(Meath): National Council for Special Education.

Sakiz, H., Sart, Z. H., Börkan, B., Korkmaz, B., \& Babür, N. (2015). Quality of life of children with learning disabilities: A comparison of self-reports and proxy reports. Learning Disabilities Research \& Practice, 30(3), 114-126. https://doi.org/10. 1111/ldrp.12060.

Scacchi, W. (2012). The future of research in computer games and virtual world environments. Irvine: Institute for Software Research, University of California.

Schwebel, D. C., Gaines, J., \& Severson, J. (2008). Validation of virtual reality as a tool to understand and prevent child pedestrian injury. Accident Analysis \& Prevention, 40(4), 1394-1400. https://doi.org/10.1016/j.aap.2008.03.005.

Shema-Shiratzky, S., Brozgol, M., Cornejo-Thumm, P., Geva-Dayan, K., Rotstein, M., Leitner, Y., et al. (2018). Virtual reality training to enhance behavior and cognitive function among children with attention-deficit/hyperactivity disorder: brief report. Developmental Neurorehabilitation, 1-6. https://doi.org/10.1080/17518423.2018.1476602.

Siegel, L. S. (2006). Perspectives on dyslexia. Paediatrics \& Child Health, 11(9), 581-587. https://doi.org/10.1093/pch/11.9.581.

Stichter, J. P., Laffey, J., Galyen, K., \& Herzog, M. (2014). iSocial: Delivering the social competence intervention for adolescents (SCl-A) in a 3D virtual learning environment for youth with high functioning autism. Journal of Autism and Developmental Disorders, 44(2), 417-430. https://doi.org/10.1007/s10803-013-1881-0.

Thompson, D., Whitney, I., \& Smith, P. K. (1994). Bullying of children with special needs in mainstream schools. Support for Learning, 9(3), 103-106. https://doi.org/10.1111/j.1467-9604.1994.tb00168.x.

Vasquez III, E., Marino, M. T., Donehower, C., \& Koch, A. (2017). Functional analysis in virtual environments. Rural Special Education Quarterly, 36(1), 17-24. https://doi.org/10.1177/8756870517703405.

Vlachou, A., Stavroussi, P., \& Didaskalou, E. (2016). Special teachers' educational responses in supporting students with special educational needs (SEN) in the domain of social skills development. International Journal of Disability, Development and Education, 63(1), 79-97. https://doi.org/10.1080/1034912X.2015.1111305.

Volioti, C., Tsiatsos, T., Mavropoulou, S., \& Karagiannidis, C. (2014, July). VLSS-Virtual Learning and Social Stories for Children with Autism. Proceedings of the 2014 IEEE 14th International Conference on Advanced Learning Technologies, 606-610. IEEE. doi: https://doi.org/10.1109/ICALT.2014.177

Wang, M., \& Reid, D. (2011). Virtual reality in pediatric neurorehabilitation: attention deficit hyperactivity disorder, autism and cerebral palsy. Neuroepidemiology, 36(1), 2-18. https://doi.org/10.1159/000320847.

Wang, S. Y., Cui, Y., \& Parrila, R. (2011). Examining the effectiveness of peer-mediated and video-modeling social skills interventions for children with autism spectrum disorders: A meta-analysis in single-case research using HLM. Research in Autism Spectrum Disorders, 5(1), 562-569. https://doi.org/10.1016/j.rasd.2010.06.023.

Wang, X., Laffey, J., Xing, W., Galyen, K., \& Stichter, J. (2017). Fostering verbal and non-verbal social interactions in a 3D collaborative virtual learning environment: a case study of youth with Autism Spectrum Disorders learning social competence in iSocial. Educational Technology Research and Development, 65(4), 1015-1039. https://doi.org/10.1007/ s11423-017-9512-7.

Wong, S. E. (2010). Single-case evaluation designs for practitioners. Journal of Social Service Research, 36(3), 248-259. https:// doi.org/10.1080/01488371003707654

Wuang, Y. P., Chiang, C. S., Su, C. Y., \& Wang, C. C. (2011). Effectiveness of virtual reality using Wii gaming technology in children with Down syndrome. Research in Developmental Disabilities, 32(1), 312-321. https://doi.org/10.1016/j.ridd.2010. 10.002 .

Zeng, N., Pope, Z., Lee, J., \& Gao, Z. (2018). Virtual reality exercise for anxiety and depression: A preliminary review of current research in an emerging field. Journal of Clinical Medicine, 7(3), 42. https://doi.org/10.3390/jcm7030042.

\section{Publisher's Note}

Springer Nature remains neutral with regard to jurisdictional claims in published maps and institutional affiliations.

\section{Submit your manuscript to a SpringerOpen ${ }^{\circ}$ journal and benefit from:}

- Convenient online submission

- Rigorous peer review

- Open access: articles freely available online

- High visibility within the field

- Retaining the copyright to your article

Submit your next manuscript at $\boldsymbol{\sim}$ springeropen.com 